\title{
Journée internationale d'études de Trieste
}

\author{
Lucia Marcheselli-Loukas
}

\section{(2) OpenEdition \\ Journals}

Édition électronique

URL : https://journals.openedition.org/ahrf/2272

DOI : 10.4000/ahrf.2272

ISSN : 1952-403X

Éditeur :

Armand Colin, Société des études robespierristes

Édition imprimée

Date de publication : 1 mars 2000

Pagination : 140

ISSN : 0003-4436

Référence électronique

Lucia Marcheselli-Loukas, « Journée internationale d'études de Trieste », Annales historiques de la Révolution française [En ligne], 319 | janvier-mars 2000, mis en ligne le 11 mai 2006, consulté le 24 avril 2022. URL : http://journals.openedition.org/ahrf/2272 ; DOI : https://doi.org/10.4000/ahrf.2272

Ce document a été généré automatiquement le 24 avril 2022.

Tous droits réservés 


\title{
Journée internationale d'études de Trieste
}

\author{
Lucia Marcheselli-Loukas
}

1 En l'honneur du bicentenaire de la capture de Rigas Velestinlis - Feraios par la police autrichienne (Trieste, 17 décembre 1797), une Journée internationale d'études s'est déroulée à Trieste le 5 décembre 1997, sous l'égide du ministère de la Culture de Grèce.

Organisée par les Sections de Langue et Littérature néogrecques des universités de Trieste et de Vérone (Italie), la journée a vu la participation de neuf spécialistes, qui ont analysé aussi bien le contexte politique et social de l'époque de Rigas, que la réception de ses idées et de sa figure dans le temps, que les aspects linguistiques et littéraires de son œuvre.

3 Notamment, M. Pashalis Kitromilidis (Athènes), a traité Rigas et les problèmes actuels dans les Balkans; Francesco Guida (Rome III), Les Principautés de Moldavie et de Valachie à l'époque de Rigas; Marco Dogo (Trieste), Les Serbes de Trieste et du Beogradski Pašaluk à l'époque de Rigas ; Prokopis Papastratis (Athènes), L'idée de la Confédération balkanique dans la période de l'entre-deux-guerres; Rena Stavridi Patrikiou (Athènes), Rigas vu par l'historiographie marxiste grecque du début du siècle; Olga Katsiardi-Hering (Athènes), Anamt tout l'entreprise: les paramètres économiques du «martyre» de Rigas; Ines Di Salvo (Palerme), Sondages de la langue de Rigas; Anna Tabaki (Athènes), Les traductions de Rigas dans le cadre des Lumières néohelleniques; Cristina Stevanoni (Vérone), Rigas traducteur de Métastase.

Les Actes du colloque seront publiés en langue italienne à Trieste, dans l'année 1999. 